\title{
The ticking time bomb in lifestyle-related diseases among women in the Gulf Cooperation Council countries; review of systematic reviews
}

\author{
Mashael K. Alshaikh ${ }^{1,2^{*}}$ (D), Filippos T. Filippidis ${ }^{1}$, Hussain A. Al-Omar ${ }^{2}$, Salman Rawaf ${ }^{1}$, Azeem Majeed
} and Abdul-Majeed Salmasi ${ }^{3}$

\begin{abstract}
Background: This study aims to review all published systematic reviews on the prevalence of modifiable cardiovascular disease risk factors among women from the Gulf Cooperation Council countries (GCC). This is the first review of other systematic reviews that concentrates on lifestyle related diseases among women in GCC countries only.

Method: Literature searches were carried out in three electronic databases for all published systematic reviews on the prevalence of cardiovascular disease risk factors in the GCC countries between January 2000 and February 2016.

Results: Eleven systematic reviews were identified and selected for our review. Common reported risk factors for cardiovascular disease were obesity, physical inactivity, diabetes, metabolic syndrome and hypertension. In GCC countries, obesity among the female population ranges from 29 to $45.7 \%$, which is one of the highest rates globally, and it is linked with physical inactivity, ranging from 45 to $98.7 \%$. The prevalence of diabetes is listed as one of the top ten factors globally, and was reported with an average of $21 \%$. Hypertension ranged from 20.9 to $53 \%$.

Conclusions: The high prevalence of lifestyle-related diseases among women population in GCC is a ticking time bomb and is reaching alarming levels, and require a fundamental social and political changes. These findings highlight the need for comprehensive work among the GCC to strengthen the regulatory framework to decrease and control the prevalence of these factors.
\end{abstract}

Keywords: Cardiovascular disease, Noncommunicable diseases, Obesity, Diabetes, Hypertension, Smoking, Physical inactivity, Metabolic syndrome, Systematic review

\section{Background}

Cardiovascular diseases (CVD's) remain the leading cause of death worldwide [1], resulting in more than 17.9 million mortalities in 2015. More than 3 million of such deaths occurred in people under the age of 60 , which could have been largely prevented [1, 2]. The World Health Organization (WHO) and other organizations such as the

\footnotetext{
* Correspondence: m.alshaikh14@imperial.ac.uk

'Department of Primary Care and Public Health, School of Public Health, Faculty of Medicine, Charing Cross Campus, St Dunstan's Road, 3rd Floor, Reynolds Building, London W6 8RP, UK

${ }^{2}$ Pharmacy Department, King Saud University, Medical City, Riyadh, Saudi Arabia

Full list of author information is available at the end of the article
}

American Heart Association (AHA) have recognized many risk factors, some of which are modifiable. These include hypertension (HTN), diabetes, obesity and metabolic syndrome (MetS) [3, 4]. In addition, many unhealthy lifestyles like smoking, physical inactivity, high consumption of carbohydrates and fatty foods have been identified as factors that increase the risk of CVD [5]. Rapid economic growth as well as urbanization have been also associated with higher consumption of unhealthy foods and lower physical activity, which may increase the risk of CVD [6].

The Gulf Cooperation Council (GCC) is a political and economic alliance of six Middle Eastern countries that includes the Kingdom Saudi Arabia (KSA), Bahrain, 
Oman, Qatar, the United Arab Emirates, (UAE) and Kuwait. The GCC was established in 1981 to ensure mutual investment and free trade between its member countries. This agreement also contributed to improvements in several fields including: education, culture, tourism, social opportunities, and health among member states [7]. Life in the GCC has changed dramatically after the discovery of oil, which became the main revenue for financing healthcare services. However, the recent fluctuation in the price of oil has affected the healthcare budget. Although GCC countries are examining different options to finance the healthcare service, up to this point, there is no clear alternative or implemented approach to achieve this goal $[8,9]$. In 2013, Chahine et al., calculated the direct and indirect costs of five selected non-communicable diseases (NCD) in the GCC was $\$ 36.2$ billion, where specifically, the cost of CVD and diabetes reached over $\$ 11$ billion. This cost is estimated to increase to $\$ 67.9$ billion by 2022 , which is equivalent to one and a half times the healthcare budget of the six governments (see Table 1: The direct and indirect factors of the five selected NCDs in the GCC) [10]. However, with these healthcare expenses, the current healthcare systems adopted by some of the GCC countries is below what is available in middle-income countries [9].

The prevalence of CVD risk factors, especially physical inactivity and obesity, is particularly high among women in the region [11]. This is highlighted by a report published by the Gulf Registry of Acute Coronary Events, which found that among 7900 patients with acute coronary syndrome, women had significantly higher prevalence of HTN, diabetes, and hyperlipidemia compared to men. Women were also diagnosed with unstable angina and non-ST-segment elevation myocardial infarction more frequently than men $[12,13]$. Beside, women at higher risk especially in third world countries due to less access to health service, and use of medications [14]. In addition, growing evidence shows that gender inequality in income, education, health care, nutrition and political voice are strongly associated with poor health and well-being [15], making these issues extremely relevant to Arab countries in general and GCC in particular, where gender inequality is substantial $[11,16]$. Such inequalities are reflected in the literature; studies focusing on women in GCC countries are limited, despite the magnitude of the problem. This review aims to provide a comprehensive overview of the modifiable CVD risk factors among women in GCC in order to inform clinicians and decision-makers in the region.

\section{Methods}

Electronic literature searches for all systematic reviews published from January 2000 to February 2016 were conducted to identify all systematic reviews of CVD risk among women in the GCC region. The search was carried out in the following electronic databases: Medline, Google Scholar, and Cochrane Database (see Table 2 for search terms). No language restrictions were applied. Throughout this review, special attention was given to the modifiable risks such as HTN, diabetes, obesity, MetS, physical inactivity and smoking. Unhealthy diet, although a known CVD risk factor, was not explored in this study. The effect of diet on health is complex and different studies have focused on either overall diet patterns or individual components that include salt, sugar, fat content, fruit and vegetables, also, Also the problem with an acceptable definition of healthy diet. Hence, a comprehensive assessment of unhealthy diet would warrant a separate review. We included all systematic reviews that reported the prevalence of CVD risk factors among women in the GCC region countries. We excluded studies that reported combined data for both genders without separate prevalence for women. However, all included studies that reported the differences between genders were documented to compare gender differences in the prevalence of CVD risk factors. Any other systematic reviews from the Middle East and North Africa that included any individual GCC countries were also included. Abstracts of reviews were inspected by two authors (MA, HA) and those appearing to meet the inclusion criteria were retrieved and read in full by both authors (see Fig. 1). The quality of those studies was assessed by two authors using the Assessment

Table 1 The direct and indirect of the five selected NCD in the GCC in 2013 [10]

\begin{tabular}{llllll}
\hline & Direct cost \% & Direct cost & Indirect cost \% & Indirect cost & $\begin{array}{l}\text { Both } \\
\text { Direct } \\
\text { \& indirect }\end{array}$ \\
\hline Condition & & & & $31,000,000,000$ & Total \$37 Billion \\
Diabetes Mellitus & 26 & $6,000,000,000$ & 2 & $620,000,000$ & 6 \\
Cardiovascular & 28 & $1,560,000,000$ & 25 & $7,750,000,000$ & 25 \\
Respiratory & 17 & $1,680,000,000$ & 11 & $3,410,000,000$ & 12 \\
Neuropsychiatric & 18 & $1,020,000,000$ & 22 & $6,820,000,000$ & 21 \\
Malignant neoplasms & 11 & $1,080,000,000$ & $12,400,000,000$ & 35 \\
\hline
\end{tabular}


Table 2 selected search terms

Cardiovascular disease
(1) "Cardiovascular disease" OR "Epidemiology of cardiovascular disease"
OR "Coronary heart disease" OR "epidemiology of coronary heart
disease" OR "Vascular Diseases"
CVD risk factors
(2) "Cardiovascular risk factor" OR "coronary heart disease risk factor"
OR "stroke risk factors" OR "diabetes mellitus" OR "epidemiology of
diabetes mellitus" OR "NIDDM" OR "dyslipidemia" OR "epidemiology
of dyslipidemia" OR "hypercholesterolemia" OR "high cholesterol" OR
"smoking" OR "tobacco use" OR "Hookah Smoking" OR "Waterpipe
Smoking" OR "epidemiology of smoking" OR "hypertension" OR
"high blood pressure" OR "epidemiology of hypertension" OR
"obesity" OR "overweight" OR "BMl" OR "epidemiology of obesity" OR
"physical activity" OR "exercise" OR "epidemiology of physical activity"
OR "Metabolic Syndrome X" OR "Metabolic syndrome"
The Gulf region
(3) "Gulf region" OR "Arab countries" OR" GCC" OR "Middle east" OR
"Arabs" OR "Saudi Arabia" OR "Kuwait" OR "Oman" OR "Bahrain"
OR "Qatar" OR "United Arab Emirates" OR "UAE"
Review
(4) "Review, Multicase" OR "Review Literature" OR "Review, Academic"
OR "Review, Systematic"
(5) \#1 AND \#3
(6) \#2 AND \#3
(7) \#3 AND \#4
(8) \#1 AND \#3 AND \#4
(9) \#2 AND \#3 AND \#4

of Multiple Systematic Review Tool (AMSTAR), a tool which has been validated as a means to assess the methodological quality of systematic reviews [17]. It uses an 11 point scale, where the maximum score is 11 . Scores $0-4$ indicate low quality, 5-8 moderate quality, and 9-11 high quality [18]. The data has been extracted independently by two researchers (MA, HA). Any disagreements were resolved by discussion between them (See Table 3: Quality assessment for reviewing the systematic reviews (AMSTAR ${ }^{\circledR}$.

\section{Results}

Thirteen out of 88 systematic reviews were deemed to meet inclusion criteria; however, two of them were excluded as they report results for both genders combined $[19,20]$. As a result, only 11 of them were considered in this paper (See Figure 1). The majority of these studies are conducted in Saudi Arabia (Table 4). The quality of most of them was moderate according to the AMSTAR criteria [18]. Three studies were identified as low quality [21-23] and one as high [24]. (See Table 3 for more information).

Obesity

Six systematic reviews reported the prevalence of obesity among women in the GCC region. Most of them adopt

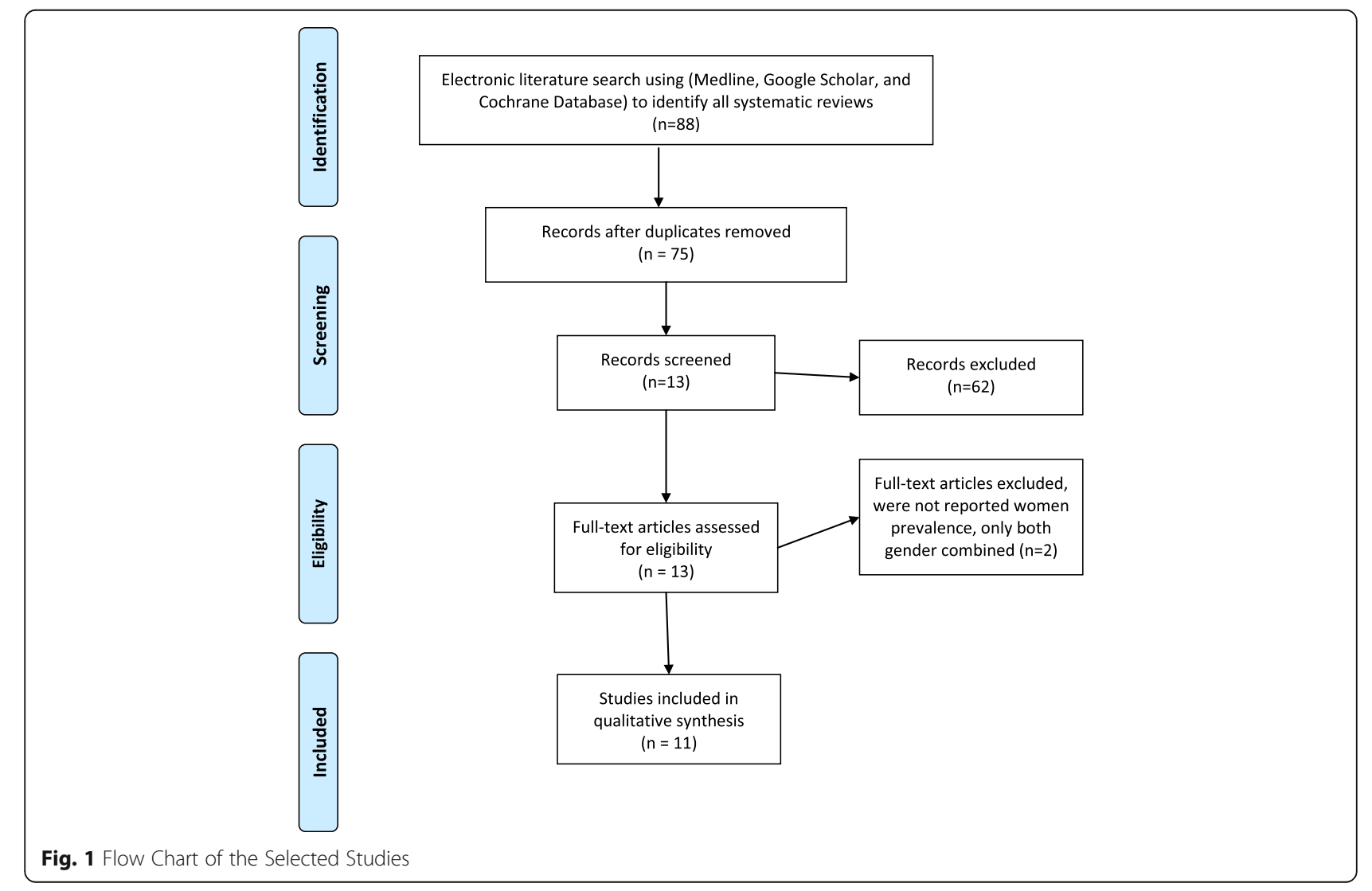




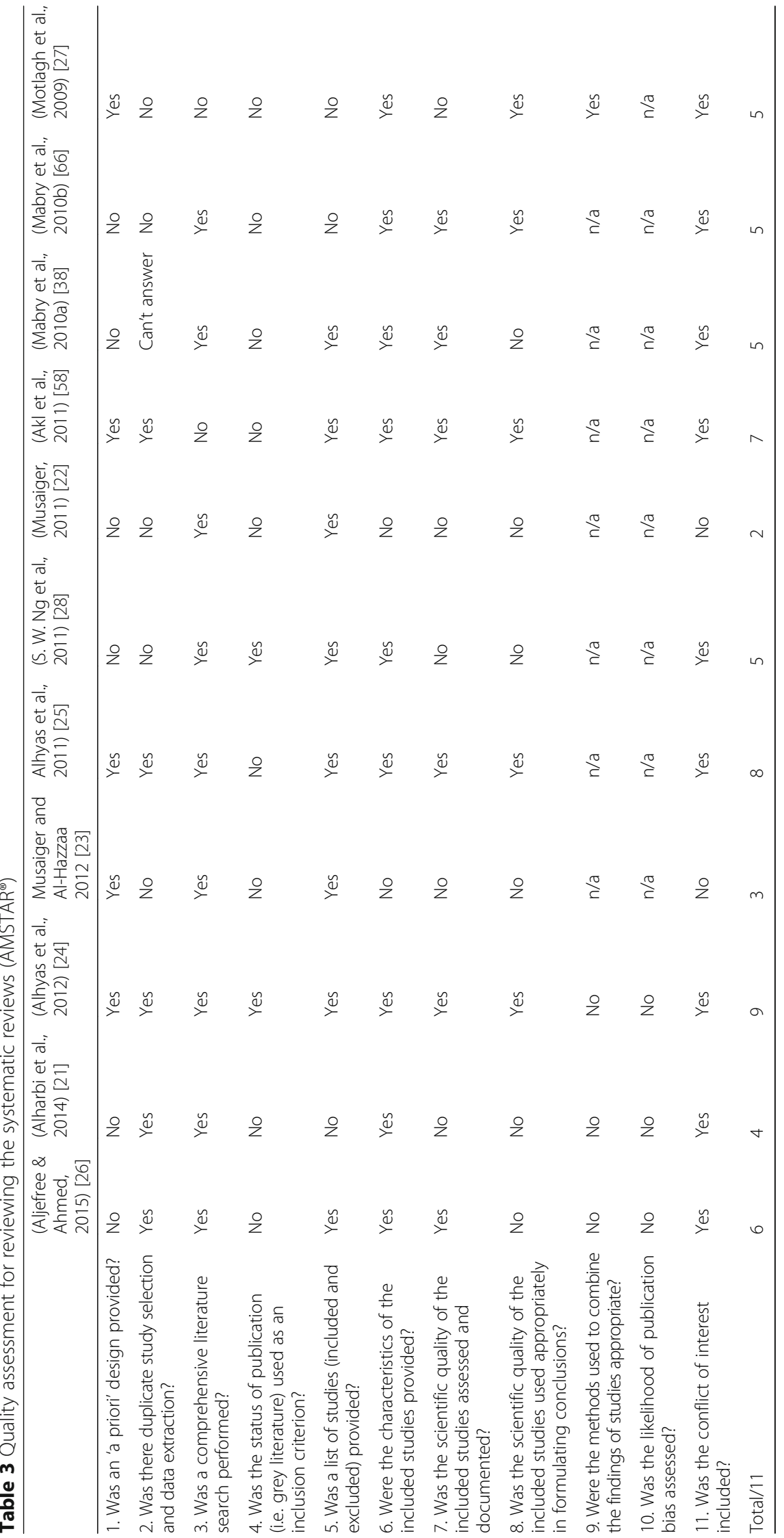




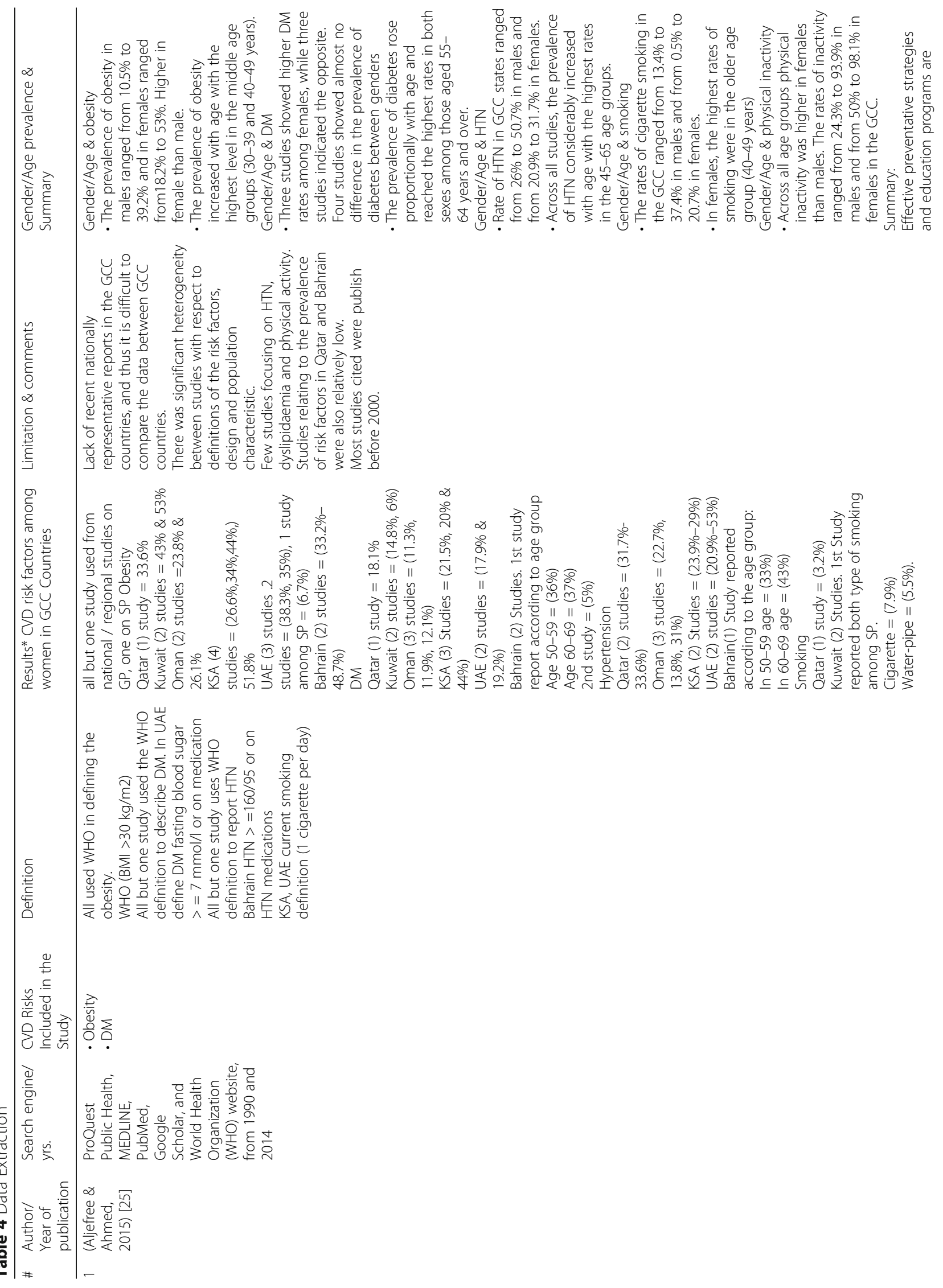




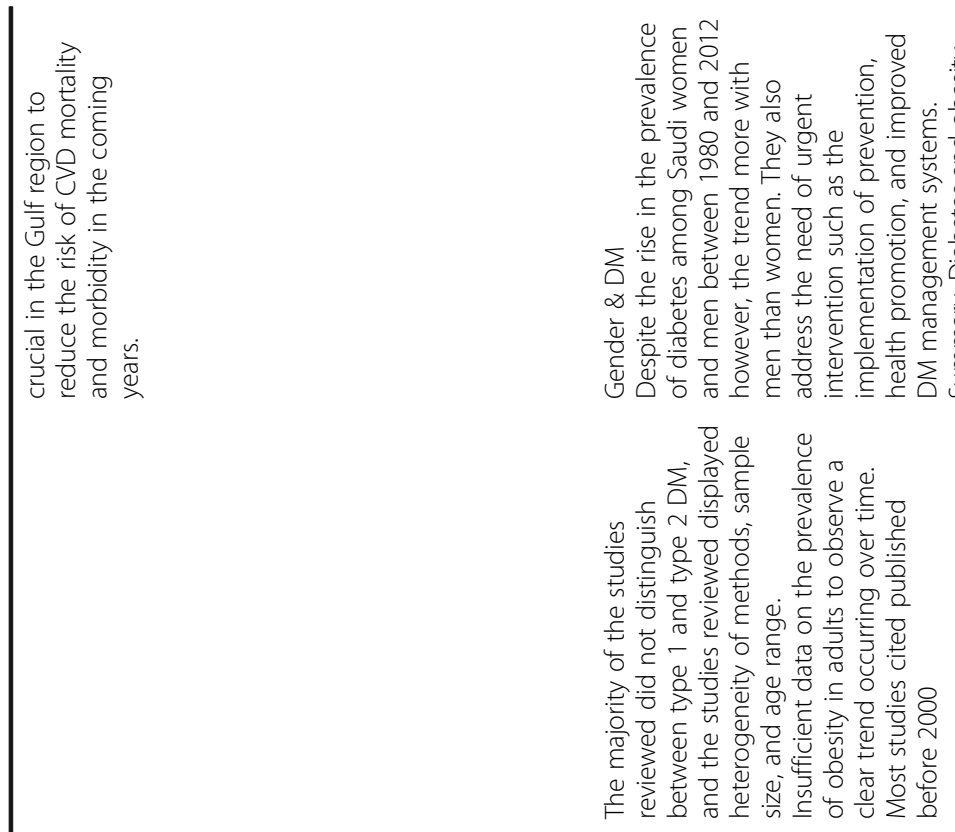

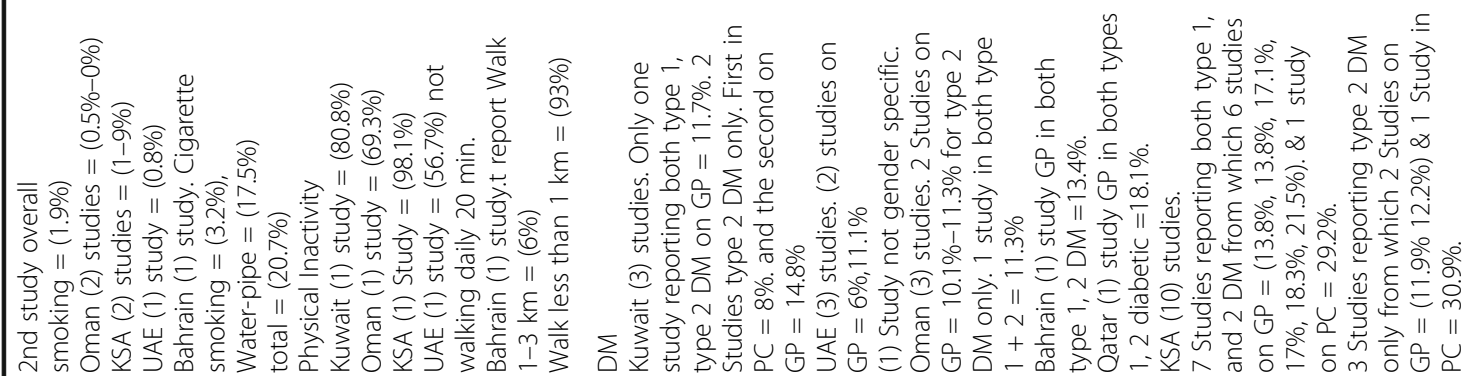

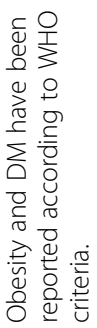

ํ. 을

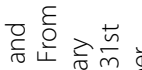

航

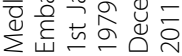

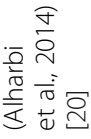

$\sim$ 

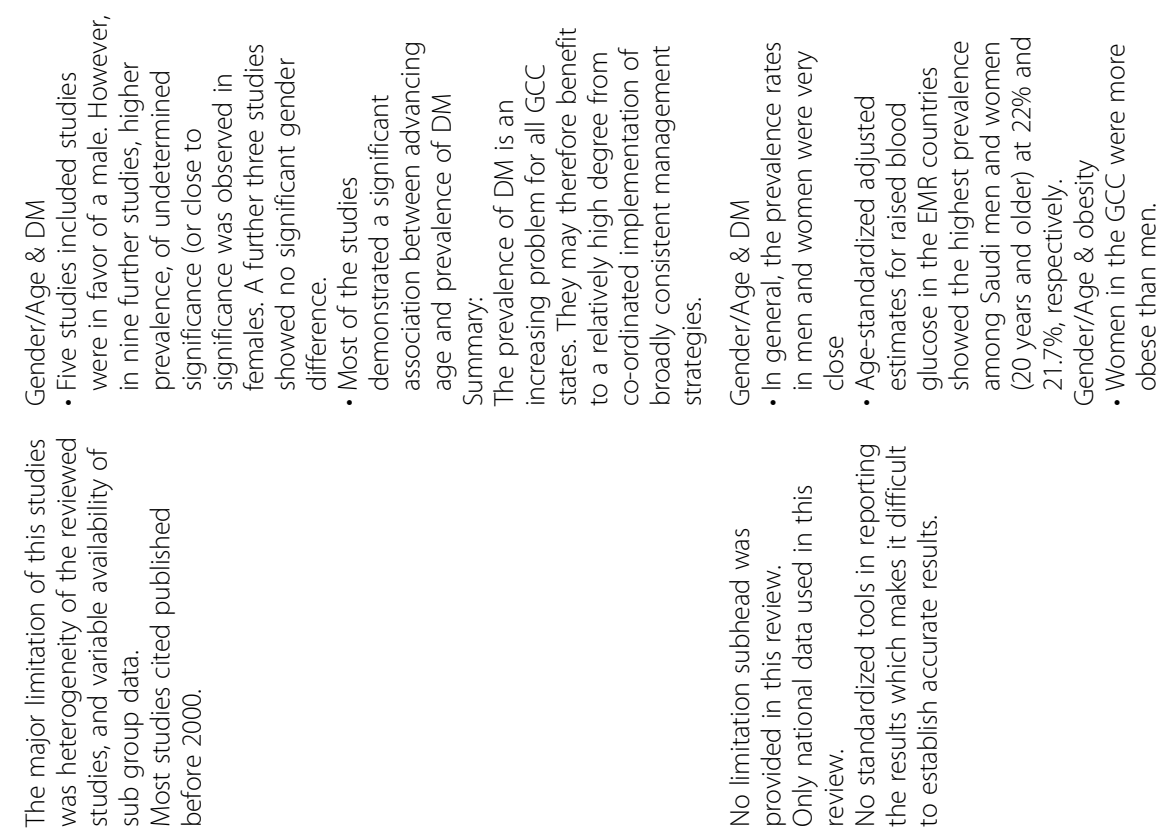

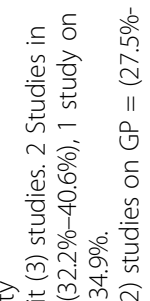
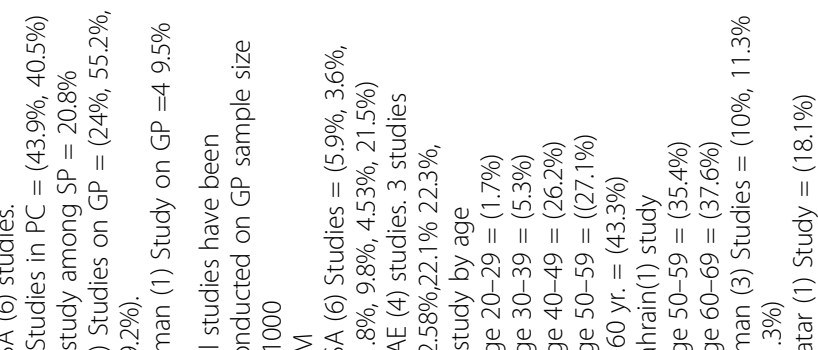

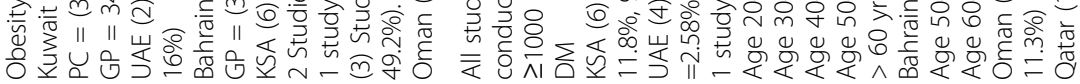
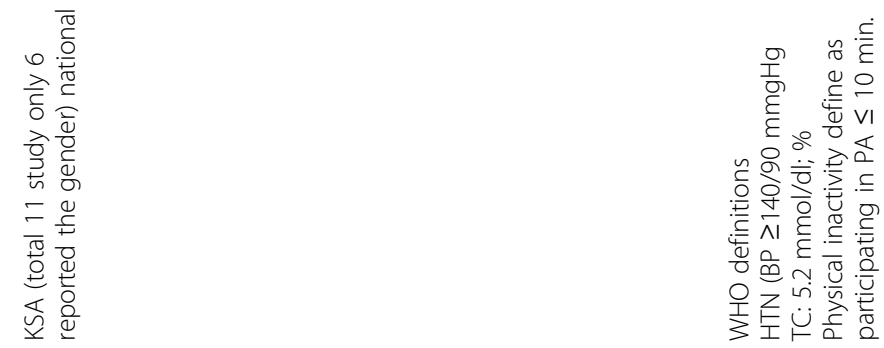

$\stackrel{\sum}{9}$

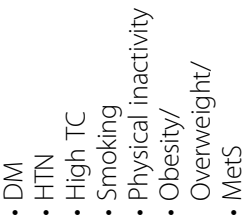

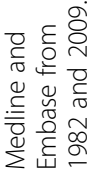

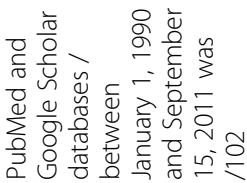

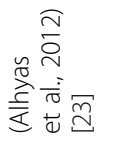

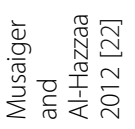



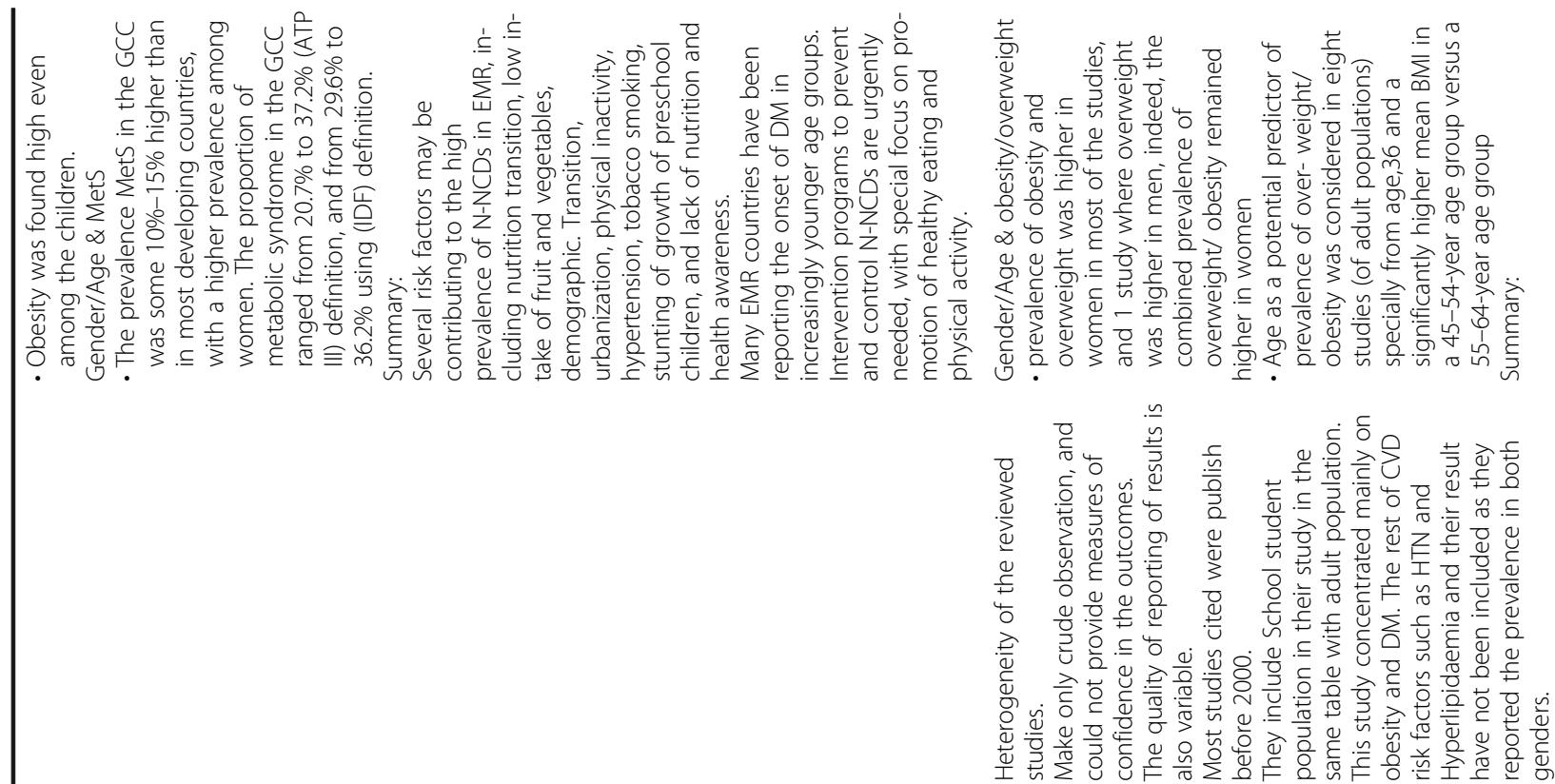

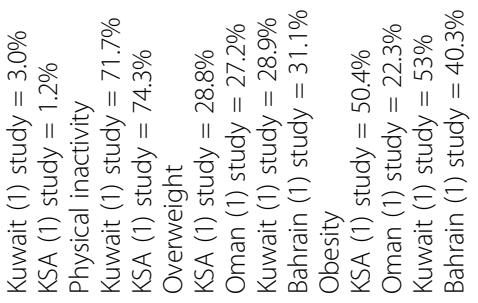
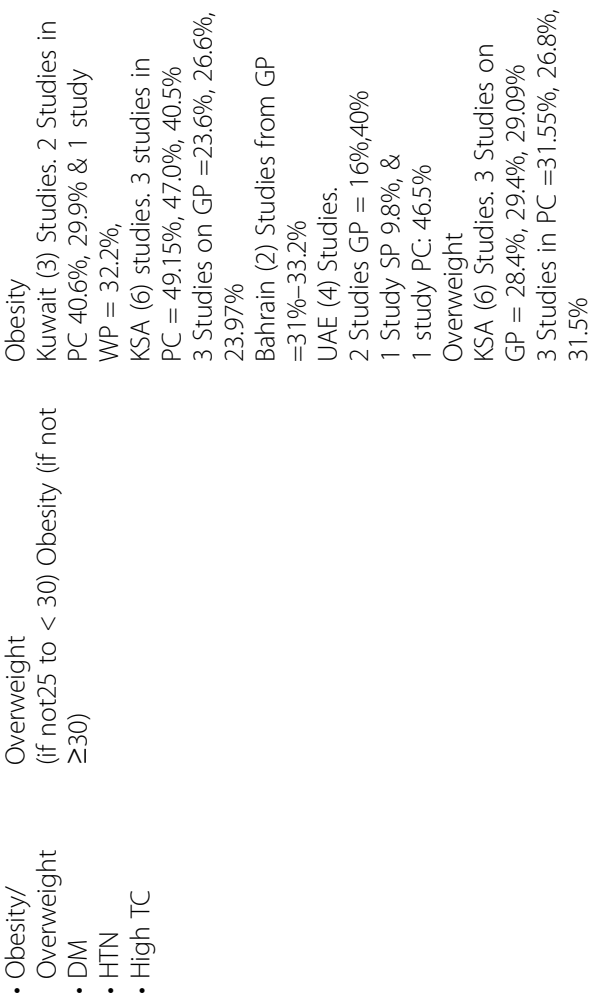

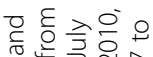

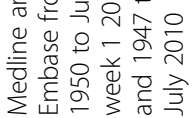

ते

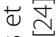

总竞

เก 

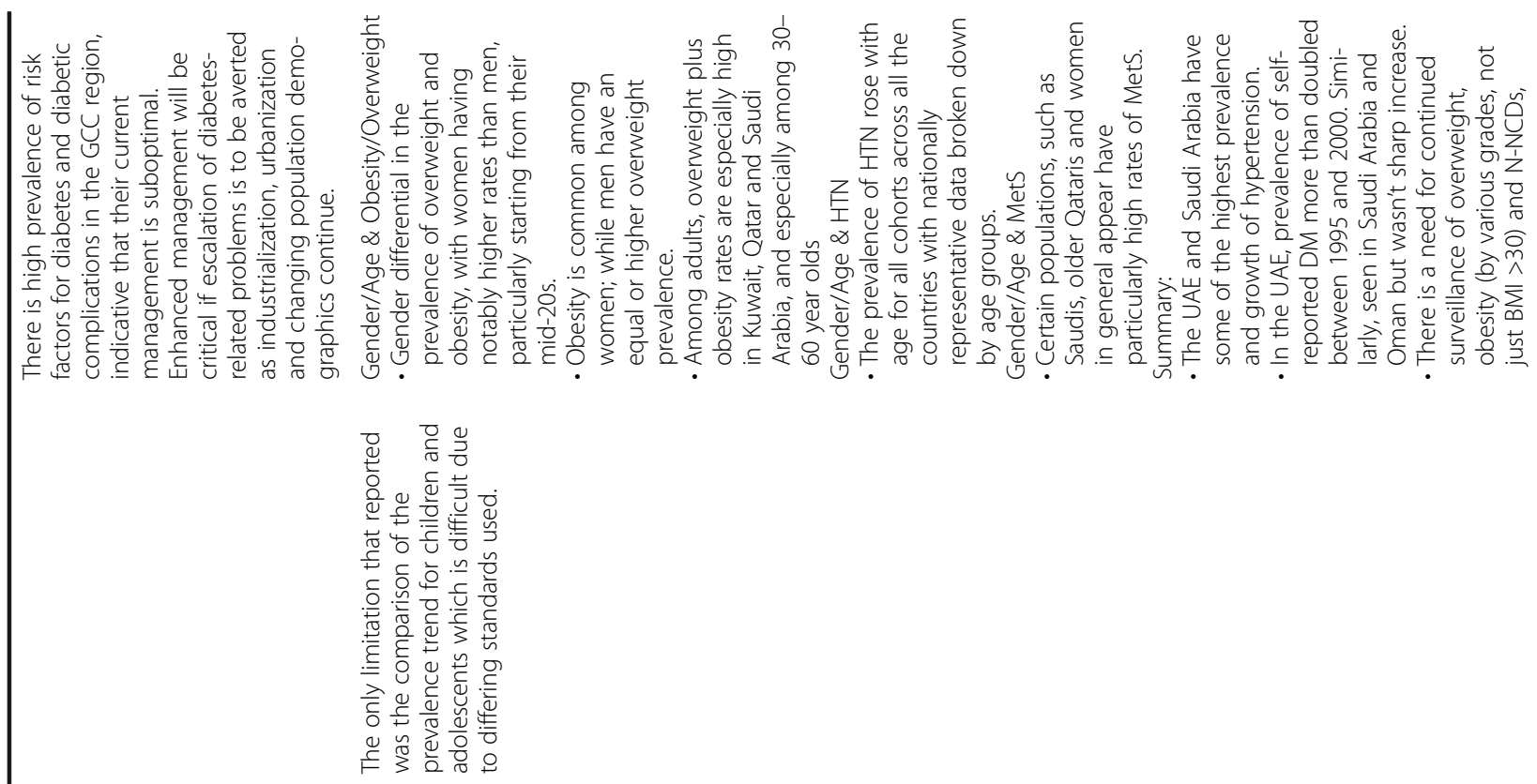

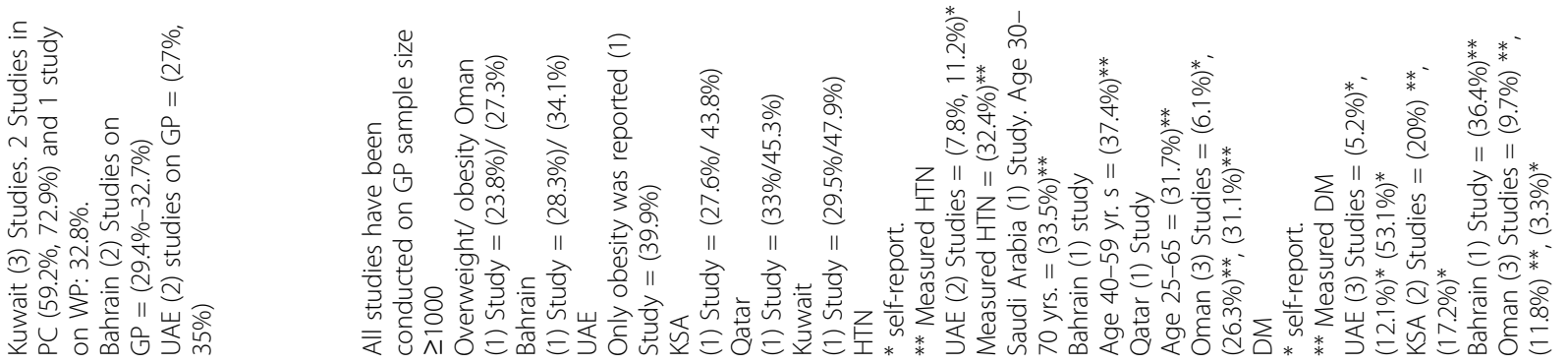

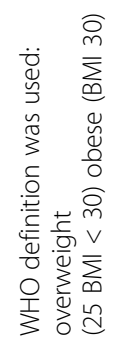

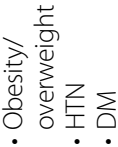

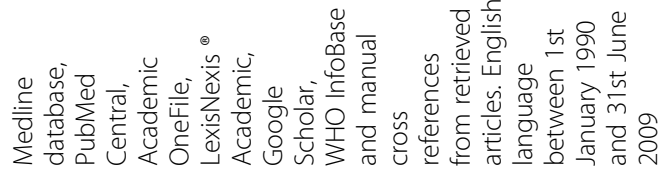

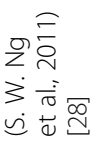



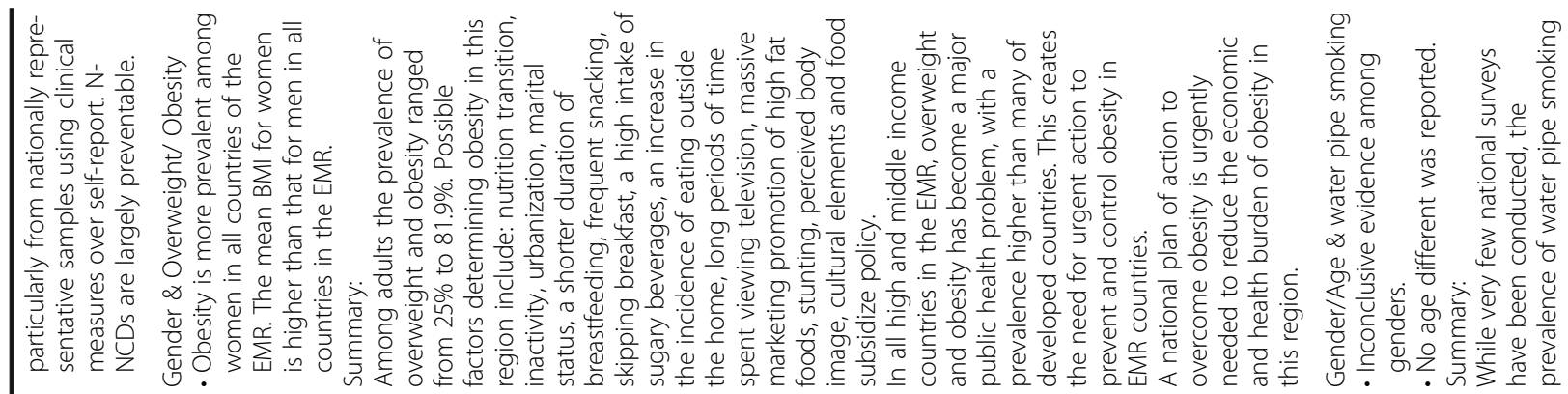

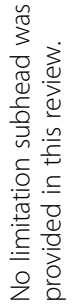

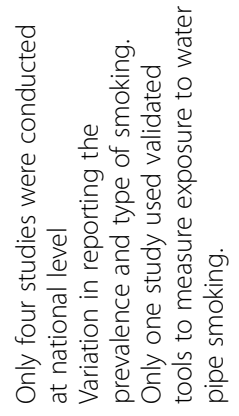

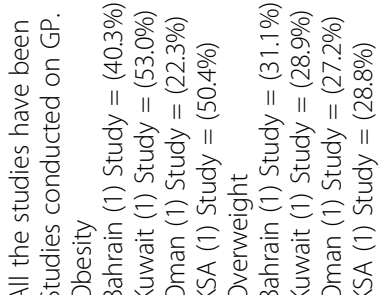

बें

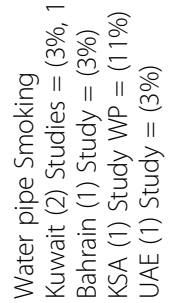

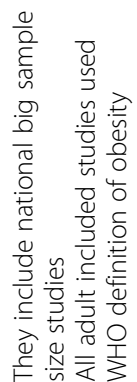

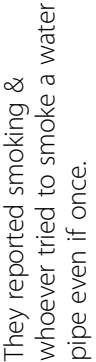

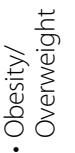

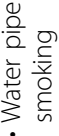

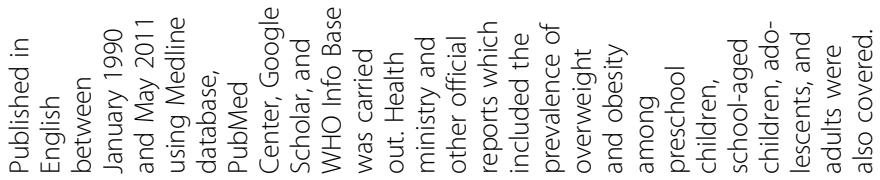

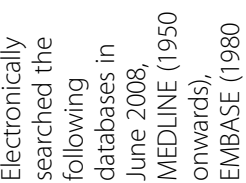

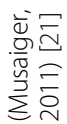

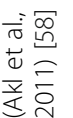

$\infty$ 


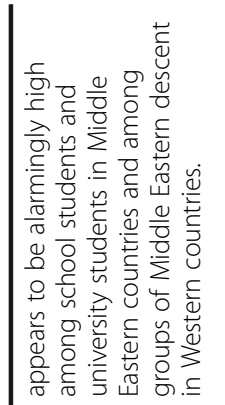

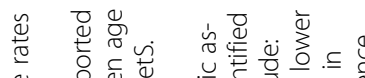

品

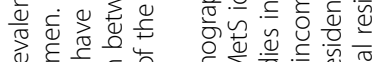

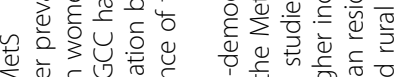

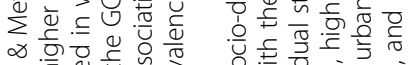

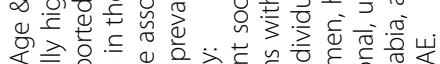

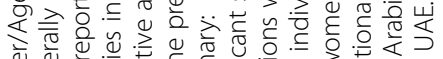

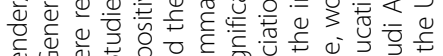

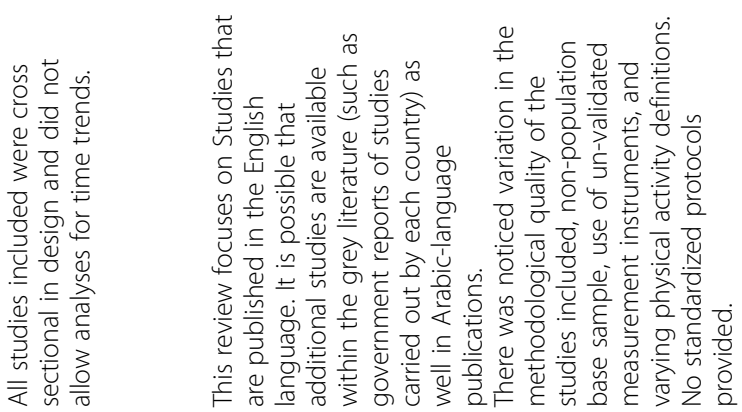

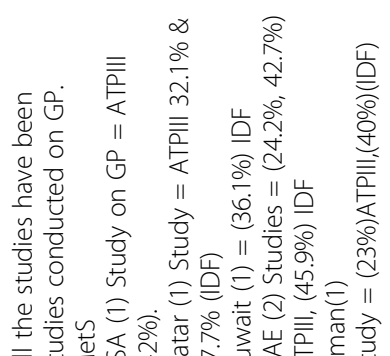

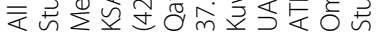

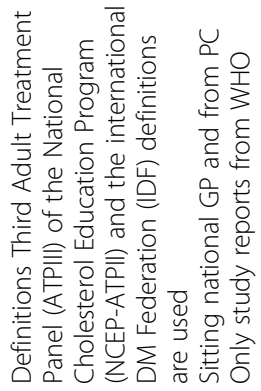

$\sum_{\substack{0 \\ 0}}^{0}$

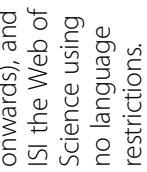

둥

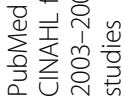

远

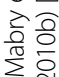

a

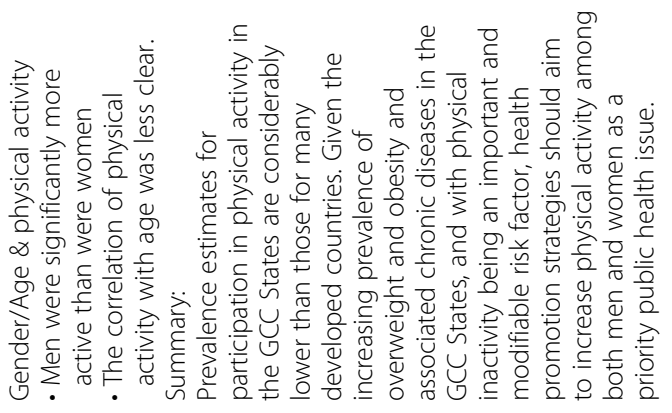

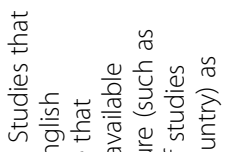

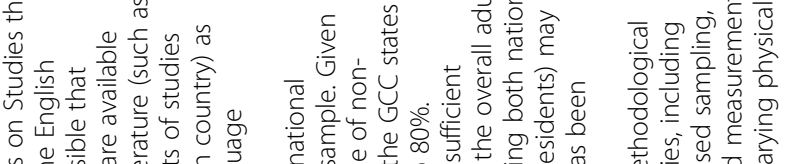

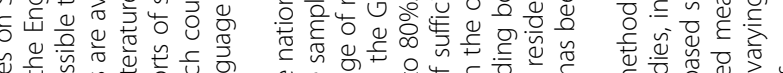

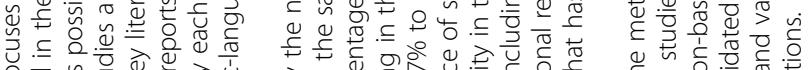

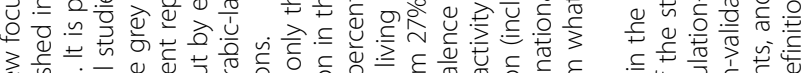

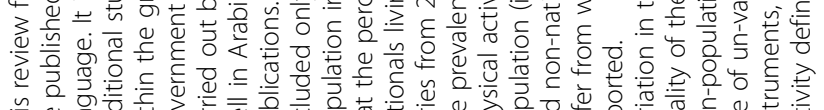

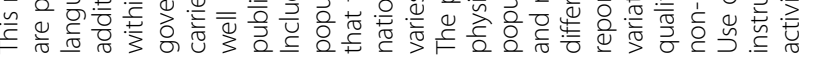

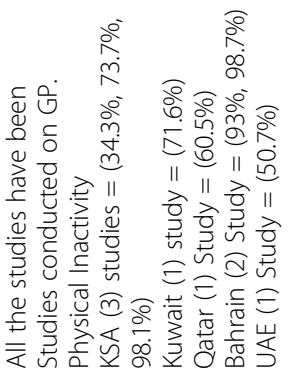

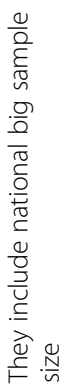



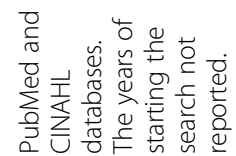

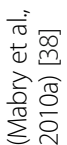

은 


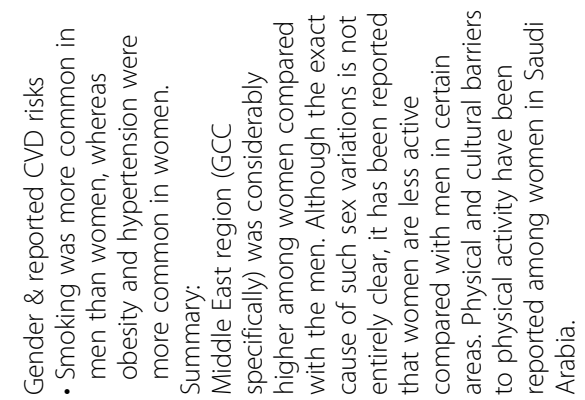

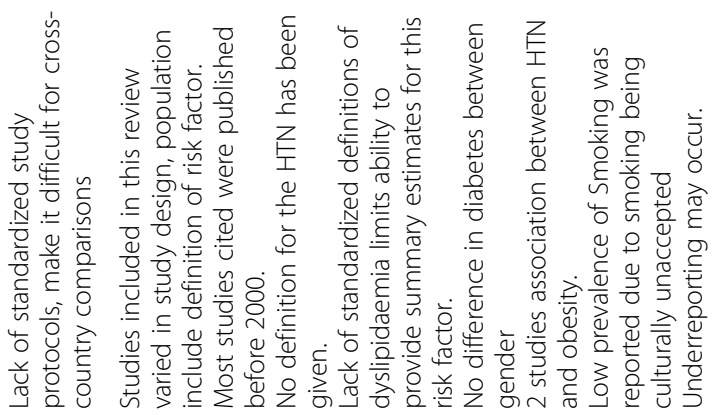

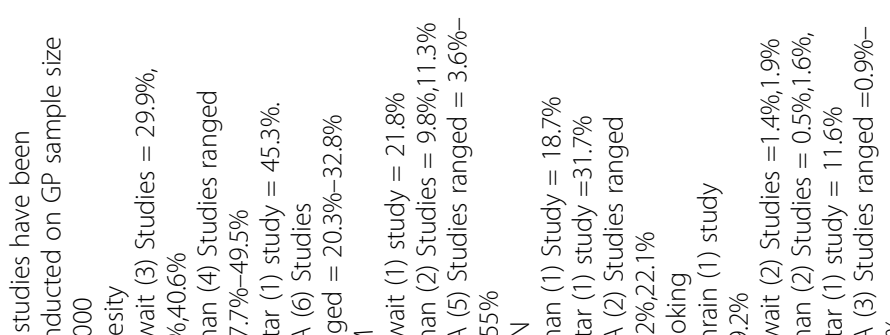

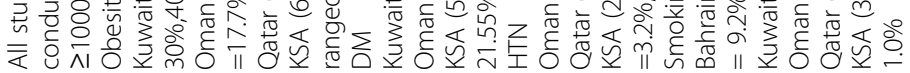

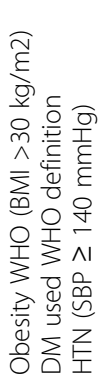

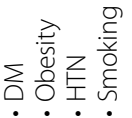

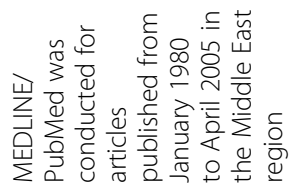

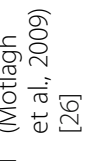


the WHO definition for BMI, identified as an indicator for obesity (obese: $\mathrm{BMI} \geq 30.0 \mathrm{~kg} / \mathrm{m}^{2}$ ). The prevalence of obesity among women in the GCC is high and ranges from $29.2 \%$ up to $45.3 \%$. The highest prevalence was among Qatari women (45.3\%); the prevalence was 38.4\% in KSA and $35.2 \%$ in Kuwait. The lower prevalence levels are reported in UAE (31.3\%) and Oman (29.2\%) $[21,22,25-28]$. While obesity has greater prevalence in women than men, being overweight is more prevalent among men within the GCC (See Table 4).

\section{Physical inactivity}

The prevalence of physical inactivity among the female population in the GCC region is reaching an alarming level, ranging from 50.7 to $98.7 \%$. In 2007 Al-Nozha et al., reported the rate of physical inactivity from a large national health survey in Saudi Arabia, the result was shocking, 96\% in both sex, and more was among women 98.1\% [29]. Bahraini women share the same high level of physical inactivity with a prevalence of up to $98.7 \%$, including a study showing that $93 \%$ of Bahraini women walk less than $1 \mathrm{~km}$ daily. Furthermore, the prevalence of physical inactivity among Kuwaiti women stands between 71.6 and $80.8 \%$. The reviews in Qatar and Oman report a prevalence from 60.5 to $69.3 \%$ respectively. UAE stands at $50.7 \%$, however, $56.7 \%$ of the women were inactive to the extent that they were reported to have not walked for longer than 20 min a day $[26,30]$.

\section{Diabetes}

The prevalence of diabetes is high within the GCC countries. Five systematic reviews have reported such a prevalence based on sample size, $>500$, mainly from national surveys. Most of the studies use the WHO definition for diabetes [21, 24, 26-28]. However, several studies within the reviews combined both types of diabetes (type 1 and type 2). The prevalence among women in the GCC ranges between 6 and 44\%, averaging 21\% [26]. Studies (before the year 2000) report low prevalence of diabetes while reviews citing more recent studies report higher prevalence rates. For example, the review by Alhyas et al. which includes relatively new data shows higher prevalence of diabetes [24]. The prevalence of diabetes in the GCC region is higher among people above $50[24,26]$. Unlike obesity, there is no clear gender gap in diabetes (See Table 4).

\section{Hypertension (HTN)}

Four systematic reviews reported the prevalence of HTN in women in the GCC [23, 26-28]. An additional study did not take gender into consideration [25]. HTN among Qatari women ranges from 31.7 to $33.6 \%$, while $33-43 \%$ of women between 50 and 69 years old were hypertensive in Bahrain. Two studies within the reviews in UAE report contradictory results.
The Aljefree and Ahmed review reports a prevalence between 20.9 to $53 \%$ while $\mathrm{Ng}$, Shu Wen et al., estimated the prevalence of HTN between $7.8 \%$ to $11.2 \%$. This result was based on self-reported data, whereas HTN measured in the same region was $32.4 \%$ [28]. Similarly, blood pressure values measured among Omani women are higher compared to selfreports $(31.1 \%$ vs $6.1 \%)$ [28]. Self-reported HTN underestimates the actual prevalence of HTN because of its non-symptomatic appearance. As for Saudi Arabia, Motlagh and colleagues reported that the HTN prevalence among Saudi women ranged from $3.7 \%$ to $22.1 \%$ between 1996 and 1997 [27]. More recent studies in the review conducted by Aljefree and Ahmed show a range between $23.9 \%$ and $33.5 \%$ [26]. There were a limited number of studies that reported the prevalence among the Kuwaiti population within these reviews. With regards to gender differences, several studies have revealed slightly greater prevalence of HTN in men [20, $25,26,31]$.

\section{Smoking}

Three reviews have reported the prevalence of smoking $[26,27,32]$. It is generally lower among women than men within the GCC region. Motlagh et al., showed that women from Qatar and Bahrain have a higher prevalence of smoking than in other GCC countries at 11.6 and 9.2\% respectively, while in Saudi Arabia, Oman, and Kuwait, the prevalence ranged between 0.5 and $1.6 \%$ [27]. Aljefree \& Ahmed found in their review that the prevalence of smoking among women in Saudi Arabia in 2003 was 9\%, while in Oman it was $0.5 \%, 0.8 \%$ in UAE, $7.9 \%$ in Kuwait, and the highest prevalence was in Bahrain (20.7\%), which was mainly water pipe smoking [26]. Currently, though, water pipe smoking is increasing among GCC women. The majority of the GCC countries have a similar prevalence of water-pipe smoking, which is around 3\% of women. Only one study states that the percentage of Saudi women smoking water pipes is $11 \%$ [32].

\section{Metabolic Syndrome (MetS)}

The overall prevalence of MetS among women in the GCC countries is reported by Mabry et al. using the definitions of the National Cholesterol Education ProgramAdult Treatment Panel III (NCEP-ATP III) ${ }^{1}$ and the International Diabetes Federation (IDF). ${ }^{2}$ Based on ATP III criteria, the prevalence of MetS in the UAE is high $(42.7 \%$ ATP III), 42\% ATP III among Saudi women, and an ATP III score of $32.1 \%$ in Qatari women. The lowest prevalence, however, can be found among Omani women, with 23\% ATP III [33]. The prevalence in some countries has been reported using IDF criteria instead of ATP III. In UAE, it is $45.9 \%$ IDF while in Qatar it is $37.3 \%$ IDF, and the lowest is in Kuwait at $36.1 \%$ IDF according to the 
studies we examined. No data on prevalence of MetS among female population in Bahrain was reported.

\section{Discussion}

Our review showed that the prevalence of major lifestylerelated risk factors for CVD is very high among women in GCC countries and seem to be increasing over the past decades.

Obesity among Arab women is highly prevalent, with the greatest increase reported in the literature among Middle Eastern countries in the six GCC countries [34]. The prevalence of obesity among women in GCC countries is higher than in countries such as Iraq, Libya, Algeria as well as European countries [35]. With regards to the marital status, married women within the GCC are more susceptible to obesity than unmarried one [35]; one of the possible reasons is that married couples are less active and tend to eat together, which may reinforce increased food intake [36]. The WHO has announced that Gulf countries have the highest prevalence of obesity, mainly among Kuwaiti, KSA, and Bahraini women [37]. The Middle East is recording the fastest increase in obesity prevalence over time, with more women than men being obese [34]. This may be attributed to multiple factors; for example the majority of households in this region, especially in Kuwait and Saudi Arabia, commonly hire housemaids which could lead to low activity and sedentary lifestyle [38]. In addition, high consumption of fast foods (high in fat and carbohydrates) combined with a sedentary lifestyle which are norms in today's GCC have played an important role in increasing levels of obesity in recent years [39, 40]. Multiple pregnancies can also contribute to weight gain, as women may retain an average of $4.5 \mathrm{~kg}$ after each birth [41].

Physical inactivity is a global public health problem. Around $31 \%$ of adults aged 15 and over were insufficiently active in 2008, with women being less active than men (34\% vs $28 \%$ ) [42]. Physical inactivity is very common in the Muslim world especially among Arabs. Based on data from 163,556 participants in 38 Muslim countries, Arab women were more likely to be physically inactive than non-Arab women (Odds Ratio $=2.15,95 \%$ CI: 2.09-2.21) [43]. Also, in a study conducted by Daryani et al, Arab immigrants in Sweden reported a higher prevalence of abdominal obesity than Swedish-born women, and a high degree of physical inactivity during leisure time, highlighting potential cultural factors [44]. Sedentary lifestyle is very common, especially among women in the Middle Eastern countries. This could be due to various reasons. In countries such as Saudi Arabia, physical education was not included in the public girl's school curriculum until early 2013 and women are still forbidden from driving, which limits their access to fitness centers [45]. Other barriers may include the desert climate, high temperatures and frequent sand storms, which makes it difficult to exercise outdoors, the lack of social support, and the common use of cheap migrant labor for household work [46].

Diabetes is a complex disease that is linked between multiple genetic and environmental factors including diet, lifestyle, and obesity [47]. Several studies show that Arabs have a greater genetic predisposition to diabetes than Caucasians [48, 49]. In Saudi Arabia, like other GCC countries, the prevalence of consanguinity is as high as $60 \%$, which is considered the highest rate of consanguineous marriages in the world $[50,51]$ and has contributed to the high prevalence of diabetes within the GCC countries [52, 53]. Additionally, the fast urbanization and increased per capita income have had negative influences on GGC lifestyle resulting in increased sedentary lifestyle, leading to obesity [54]. Obesity is a major risk factor for developing diabetes, where in many cases, more than half of the diabetic patients were found to be obese $[55,56]$. From a cost perspective, Saudi Arabia spends $21 \%$ of their total health expenditure on diabetes, with other GCC countries spending between 16 and 19\% [57].

The prevalence of HTN was also high among women in GCC countries. Data from the Second Gulf Registry of Acute Coronary Events (Gulf RACE-2) showed that $47.2 \%$ of the registered individuals were hypertensive, and women were more likely to have HTN than men [13, 58]. In 2014 El Bcheraoui et al., reported the prevalence of HTN from a large national health survey of more than 10,000 households throughout KSA. The overall prevalence was $15.2 \%$ of those with hypertension were found to be undiagnosed [59]. Underreporting should not be ruled out, as many of the studies included collected self-reported data [28]. Likewise, a study published in Saudi Arabia also showed that almost $40 \%$ of people affected by HTN were unaware of their disease at the time of the survey [60].

Low prevalence of smoking among women in the GCC countries could be an indication of under reporting, as smoking cigarettes traditionally is not accepted among Arab Muslim women, especially in the GCC countries [61]. In contrast, the acceptance and popularity of water pipe smoking is very common among Arabs in general, especially women [62-66]. There is also a false perception that water pipe smoking is less harmful than cigarettes [67]. Up to this point, the data shows a growing trend of women smoking water pipes in the GCC countries, but it is still less than other neighboring Arab countries [32].

\section{Limitations}

The heterogeneity of the reviewed studies and variable availability of sub-group data was a major limitation in the review process within the GCC countries. We 
presented the actual reported percentage or the range of percentages in the cited studies that pertain to the prevalence of CVD risk factors among women. However, some studies do not report the actual percentage pertaining to the women studied and just presents the total percentage of both genders or male population only. Some studies were mixing adult and children within their included studies, hence some reported low prevalence. Moreover, some studies do not cover all the six members of the GCC countries, with some systematic reviews that present data from only two to three countries in the GCC region.

\section{Policy implications}

This review indicated high levels of modifiable risk factors among women. Gender inequality damages the physical and mental health of millions of women across the globe. A continuous rising prevalence of lifestylerelated diseases increases the need for gender equality throughout the GCC countries, especially for Saudi Arabian women, to empower them in regards to their role in the society, their decision-making and more involvement in health care. Obesity is the major risk factor of CVDs in GCC countries and linked too many other NCDs. Women in GCC countries are facing a major struggle in challenging physical inactivity, which results in one of the highest obesity rates globally. Al-Bahilani and Mabry reported the legislations and policies issued by the GCC in regards behavioral risk of NCD, where most of them were related to tobacco control. However, in regards to the prevention of NCDs, only six policies have been addressed by the GCC's ministries of health [68]. In 2012-2013, the GCC Secretary General, implemented short and long-term action plans to tackle NCDs, where short-term actions included "incentives and disincentives (such as taxes on tobacco), regulations (for example, limiting the availability of unhealthy food in schools), and clinical interventions (for instance, screening the population for risk factors)" [10].

Introducing a more active lifestyle by expanding the field of physical education through the GCC region and sports competitiveness among women is highly recommended. It is important to present a more elementary approach in measuring obesity levels by reporting central obesity with the combination of BMI, waist circumference and waist/hip ratio to obtain more accurate results. There is a high requirement for diet control and awareness in regards to total daily calorie intake. Although food labeling was introduced by the GCC customs union, the labeling requirements are basic and do not require regulations regarding the nutrition content of processed foods, such as sodium content and transfat [68]. Additionally, the direct and indirect costs of care and treatment of patients suffering from these diseases are significant and will become more burdensome as the price of oil has declined, and is likely to remain at lower levels due to the increased global supply. The data suggest that applying preventative measures for diabetes and CVD would potentially save $54 \%$ of the direct costs and $31 \%$ of the total cost of treatment. This results in not only a significant savings, but improved quality of life for the patients [10] and magnifies why the healthcare sector needs to focus more on preventable measures, such as motivating society to adopt healthy lifestyles. Implementing the health belief model and understanding health-related behavior among the female population in the GCC countries in regards to CVD and its risk factors would help in understanding why women are not adopting a healthier lifestyle.

\section{Conclusion}

The high prevalence of lifestyle-related diseases among women population in GCC is a ticking time bomb and is reaching alarming levels, and require a fundamental social, cutural and political changes. These findings highlight the need for comprehensive work among the GCC to strengthen the regulatory framework to reduce and control the prevalence of these factors.

\section{Endnotes}

${ }^{1}$ NCEP ATP III definition, metabolic syndrome is present if three or more of the following five criteria are met: waist circumference over $40 \mathrm{in.} \mathrm{(men)} \mathrm{or} 35 \mathrm{in}$. (women), blood pressure over 130/85 $\mathrm{mmHg}$, fasting triglyceride level over $150 \mathrm{mg} / \mathrm{dl}$, fasting high-density lipoprotein (HDL) cholesterol level less than $40 \mathrm{mg} / \mathrm{dl}$ (men) or $50 \mathrm{mg} / \mathrm{dl}$ (women) and fasting blood sugar over $100 \mathrm{mg} / \mathrm{dl}$.

${ }^{2}$ IDF definition includes the same general criteria as the other definition; it requires that obesity, but not necessarily insulin resistance, be present.

\begin{abstract}
Abbreviations
AHA: American heart association; AMSTAR: Assessment of multiple systematic review tool; ATP III: Adult treatment panel III; BMI: Body mass index;

CVD: Cardiovascular disease; DALYs: Disability-adjusted life years; GCC: Gulf cooperation council; HBM: Health belief model; HTN: Hypertension;

IDF: International diabetes federation; KSA: Kingdom of Saudi Arabia; MetS: Metabolic syndrome; NCEP: National cholesterol education program; UAE: United Arab Emirates; WHO: World health organization
\end{abstract}

\section{Acknowledgments}

The authors would like thank Ms. Juren Baldove (Department of Critical Care, King Saud University Medical City. Riyadh, Saudi Arabia) for all the help in data extraction.

\section{Funding}

This research was supported by sponsorship provided to Mashael K Alshaikh, by King Saud University, Riyadh, Saudi Arabia. The Department of Primary Care and Public Health at Imperial College London is grateful for support from the National Institute for Health Research (NIHR) Collaboration for Leadership in Applied Health Research \& Care (CLAHRC) scheme, the NIHR Biomedical Research Centre scheme, and the Imperial Centre for Patient Safety and Service Quality. 


\section{Authors' contributions}

MA, FF and SR prepared the study protocol. This included designing the search strategy, helping in selecting studies for inclusion and developing a data extraction form. MA and $\mathrm{HA}$ also helped in selecting studies for inclusion. MA and HA carried out the search, identified potential studies for inclusion, extracted the data, assessed the quality of the included studies, and carried out the data analysis under the supervision of SR and AM and FF wrote the manuscript, which was then revised by SR, AM and AS. All the authors have approved the final version. The guarantor is MA.

\section{Competing interests}

The authors declare that they have no competing interests.

\section{Consent for publication}

Not applicable.

\section{Ethics approval and consent to participate}

Not applicable.

\section{Publisher's Note}

Springer Nature remains neutral with regard to jurisdictional claims in published maps and institutional affiliations.

\section{Author details}

'Department of Primary Care and Public Health, School of Public Health, Faculty of Medicine, Charing Cross Campus, St Dunstan's Road, 3rd Floor, Reynolds Building, London W6 8RP, UK. Pharmacy Department, King Saud University, Medical City, Riyadh, Saudi Arabia. ${ }^{3}$ National Heart \& Lung Institute, Faculty of Medicine, Imperial College London, London, UK.

\section{Received: 18 October 2016 Accepted: 27 April 2017}

Published online: 02 June 2017

\section{References}

1. Wang H, Naghavi M, Allen C, Barber RM, Bhutta ZA, Carter A, et al. Global, regional, and national life expectancy, all-cause mortality, and cause-specific mortality for 249 causes of death, 1980-2015: a systematic analysis for the Global Burden of Disease Study 2015. Lancet. 2016;388(10053):1459-544.

2. Mendis S, Puska P, Norrving B. Global Atlas on cardiovascular disease prevention and control [http://whqlibdoc.who.int/publications/2011/ 9789241564373_eng.pdf]

3. Bitton A, Gaziano TA. The Framingham Heart Study's impact on global risk assessment. Prog. Cardiovasc. Dis. 2010;53(1):68-78

4. Prevention of Cardiovascular Disease Guidelines for assessment and management of cardiovascular risk [http://www.who.int/cardiovascular_ diseases/guidelines/Full text.pdf]

5. Chomistek AK, Chiuve SE, Eliassen AH, Mukamal KJ, Willett WC, Rimm EB. Healthy lifestyle in the primordial prevention of cardiovascular disease among young women. J. Am. Coll. Cardiol. 2015;65(1):43-51.

6. Who J, Consultation FE. Diet, Physical Activity and Health [http://www.who. int/dietphysicalactivity/publications/trs916/intro/en/]

7. SecretariatGeneraloftheGulfCooperationCouncil. The Cooperation Council for the Arab States of the Gulf [http://www.gcc-sg.org/en-us/Pages/default.aspx]

8. Sturm M, Strasky J, Adolf P, Peschel D. The Gulf Cooperation Council Countries-Economic Structures, Recent Developments and Role in the Global Economy. ECB occasional paper. 2008;92

9. Alkhamis A, Hassan A, Cosgrove P. Financing healthcare in Gulf Cooperation Council countries: a focus on Saudi Arabia. Int. J. Health Plann. Manag. 2014;29(1):e64-82

10. Chahine G, Bitar J, Assouad P, Abi Chaker S. The $\$ 68$ billion challenge, quantifying and tackling the burden of chronic diseases in the GCC. Illinois: Booz \& Co. 2013. Available from: [http://www.booz.com/me/home/ thought_leadership_strategy/reports_and_white_papers_me/display/the-68billiondollar-challenge?cm_mid=3108890\&cm_crmid=95462fe6-3e45-475abb64-5f541513f176\&cm_medium=email] Accessed 24 Mar 2014

11. Rahim HF, Sibai A, Khader Y, Hwalla N, Fadhil I, Alsiyabi H, et al. Noncommunicable diseases in the Arab world. Lancet. 2014;383(9914):356-67.

12. Shehab A, Al-Dabbagh B, AlHabib KF, Alsheikh-Ali AA, Almahmeed W, Sulaiman $K$, et al. Gender disparities in the presentation, management and outcomes of acute coronary syndrome patients: data from the 2nd Gulf Registry of Acute Coronary Events (Gulf RACE-2). PloS one. 2013;8(2):e55508.
13. Alhabib KF, Sulaiman K, Al-Motarreb A, Almahmeed W, Asaad N, Amin H, et al. Baseline characteristics, management practices, and long-term outcomes of Middle Eastern patients in the Second Gulf Registry of Acute Coronary Events (Gulf RACE-2). Ann Saudi Med. 2012;32(1):9-18.

14. Yusuf S, Islam S, Chow CK, Rangarajan S, Dagenais G, Diaz R, et al. Use of secondary prevention drugs for cardiovascular disease in the community in high-income, middle-income, and low-income countries (the PURE Study): a prospective epidemiological survey. Lancet. 2011;378(9798):1231-43.

15. World Health Organization. Women and health: today's evidence tomorrow's agenda [http://www.who.int/gender/women_health_report/ full_report_20091104_en.pdf]

16. Baliamoune-Lutz M, McGillivray M. Does Gender Inequality Reduce Growth in Sub-Saharan African and Arab Countries?*. Afr. Dev. Rev. 2009;21(2):224-42.

17. Smith V, Devane D, Begley CM, Clarke M. Methodology in conducting a systematic review of systematic reviews of healthcare interventions. BMC Med. Res. Methodol. 2011;11(1):15.

18. Shea BJ, Grimshaw JM, Wells GA, Boers M, Andersson N, Hamel C, et al. Development of AMSTAR: a measurement tool to assess the methodological quality of systematic reviews. BMC Med. Res. Methodol. 2007;7:10.

19. Zabetian A, Keli HM, Echouffo-Tcheuqui JB, Narayan KM, Ali MK. Diabetes in the Middle East and North Africa. Diabetes Res. Clin. Pract. 2013;101(2):106-22.

20. Tailakh A, Evangelista LS, Mentes JC, Pike NA, Phillips LR, Morisky DE. Hypertension prevalence, awareness, and control in Arab countries: a systematic review. Nurs. Health Sci. 2014;16(1):126-30.

21. Alharbi NS, Almutari R, Jones S, Al-Daghri N, Khunti K, de Lusignan S. Trends in the prevalence of type 2 diabetes mellitus and obesity in the Arabian Gulf States: Systematic review and meta-analysis. Diabetes Res. Clin. Pract. 2014;106(2):e30-3.

22. Musaiger AO. Overweight and obesity in eastern mediterranean region: prevalence and possible causes. J. Obes. 2011;2011:407237.

23. Musaiger AO, Al-Hazzaa HM. Prevalence and risk factors associated with nutrition-related noncommunicable diseases in the Eastern Mediterranean region. Int J Gen Med. 2012;5:199-217.

24. Alhyas L, McKay A, Majeed A. Prevalence of type 2 diabetes in the States of the co-operation council for the Arab States of the Gulf: a systematic review. PloS one. 2012;7(8):e40948.

25. Alhyas L, McKay A, Balasanthiran A, Majeed A. Prevalences of overweight, obesity, hyperglycaemia, hypertension and dyslipidaemia in the Gulf: systematic review. JRSM Short Rep. 2011;2(7):55.

26. Aljefree N, Ahmed F. Prevalence of Cardiovascular Disease and Associated Risk Factors among Adult Population in the Gulf Region: A Systematic Review. Adv Public Health. 2015;2015:23.

27. Motlagh B, O'Donnell M, Yusuf S. Prevalence of cardiovascular risk factors in the Middle East: a systematic review. Eur. J. Cardiovasc. Prev. Rehabil. 2009; 16(3):268-80.

28. Ng SW, Zaghloul S, Ali HI, Harrison G, Popkin BM. The prevalence and trends of overweight, obesity and nutrition-related non-communicable diseases in the Arabian Gulf States. Obes. Rev. 2011;12(1):1-13.

29. Ng M, Fleming T, Robinson M, Thomson B, Graetz N, Margono C, Mullany EC, Biryukov S, Abbafati C, Abera SF, et al. Global, regional, and national prevalence of overweight and obesity in children and adults during 19802013: a systematic analysis for the Global Burden of Disease Study 2013. Lancet. 2014;384(9945):766-81.

30. Badran M, Laher I. Obesity in arabic-speaking countries. J Obes. 2011;2011: 686430.

31. Jeffery RW, Rick AM. Cross-sectional and longitudinal associations between body mass index andmarriage-related factors. ObesRes. 2002;10(8):809-15.

32. World Health Organization. Obesity and Overweight: Factsheet No 311. Updated June 2016. [http://www.emro.who.int/health-topics/obesity/].

33. AL Nohair S. Obesity in gulf countries. Int J Health Sci. 2014;8(1):79-83.

34. Hurt RT, Kulisek C, Buchanan LA, McClave SA. The obesity epidemic: challenges, health initiatives, and implications for gastroenterologists. Gastroenterol Hepatol (NY). 2010;6(12):780-92.

35. Musaiger AO. Over weight and obesity in the Eastern Mediterranean Region: can we control it? East Mediterr Health J. 2004;10(6):789-93.

36. Khashoggi RH, Madani KA, Ghaznawy HI, Ali MA. Socio economic factors affecting the prevalence of obesity among female patients attending primary health centers in Jeddah, Saudi Arabia. Ecol food Nutr. 1994;31(3-4):277-83.

37. Al-Nozha MM, Al-Hazzaa HM, Arafah MR, Al-Khadra A, Al-Mazrou YY, Al-Maatouq MA, Khan NB, Al-Marzouki K, Al-Harthi SS, Abdullah M, et al. Prevalence of 
physical activity and inactivity among Saudis aged 30-70 years. A populationbased cross-sectional study. Saudi Med J. 2007;28(4):559-68.

38. Mabry RM, Reeves MM, Eakin EG, Owen N. Evidence of physical activity participation among men and women in the countries of the Gulf cooperation council: a review.Obesity Rev. 2010;11(6):457-64.

39. World Health Organization, 2012. Physical inactivity: a global public health problem. 2010. [http://www.who.int/dietphysicalactivity/factsheet_inactivity/en/].

40. Kahan D. Adult physical inactivity prevalence in the Muslim world: Analysis of 38 countries. Prev Med Rep. 2015;2:71-5.

41. Daryani A, Berglund L, Andersson A, Kocturk T, BeckerW, Vessby B. Risk factors for coronary heart disease among immigrant women from Iran and Turkey, compared towomen of Swedish ethnicity. Ethn Dis. 2005;15(2):213-20.

42. Al-Eisa ES, Al-Sobayel HI. Physical activity and health beliefs among Saudi Women. J Nutr Metab. 2012;2012:642187.

43. Benjamin K, Donnelly TT. Barriers and facilitators influencing the physical activity of Arabic adults: A literature review. Avicenna 2013;8:1-16.

44. Hu FB. Globalization of diabetes: the role of diet, lifestyle, and genes Diabetes Care. 2011;34(6):1249-57.

45. ShaatN, Ekelund M, Lernmark A, Ivarsson S, Nilsson A, Perfekt R, Berntorp K, Groop L. Genotypic and phenotypic differences between Arabian and Scandinavian women with gestational diabetes mellitus. Diabetologia. 2004; 47(5):878-84.

46. Ahlqvist E, Ahluwalia TS, Groop L. Genetics of type 2 diabetes. Clin Chem. 2011;57(2):241-54.

47. Tadmouri GO, Nair P, Obeid T, Al Ali MT, Al Khaja N, Hamamy HA. Consanguinity and reproductive health among Arabs. Reprod Health. 2009;6:17.

48. Gosadi IM, Goyder EC, Teare MD. Investigating the potential effect of consanguinity on type 2 diabetes susceptibility in a Saudi population. Hum Hered. 2014;77(1-4):197-206.

49. Abuyassin B, Laher I. Obesity-linked diabetes in the Arab world: a review. East Mediterr Health J. 2015;21(6):420-39.

50. Sherif S, Sumpio BE. Economic development and diabetes prevalence in MENA countries: Egypt and Saudi Arabia comparison. World J Diabetes. 2015;6(2):304-11.

51. Klautzer L, Becker J, Mattke S. The curse ofwealth - Middle Eastern countries need to address therapidly rising burden of diabetes. Int J Health Policy Manag. 2014;2(3):109-14

52. Memish ZA, El Bcheraoui C, Tuffaha M, Robinson M, Daoud F, Jaber S, Mikhitarian S, Al Saeedi M, Al Mazroa MA, Mokdad AH, et al. Obesity and associated factorsKingdom of Saudi Arabia, 2013. Prev Chronic Dis. 2014;11:E174

53. Musaiger ASN. The relationship between obesity and prevalence of chronic diseases in the Arab women. J Hum Ecol Special. 2005;13:97-100.

54. Al-Rubeaan K. The impact of diabetes mellitus on health and economy of Gulf Cooperation Council countries. Diabetes Manag. 2014;4(4):381-90.

55. Alshaikh MK, Filippidis FT, Baldove JP, Majeed A, Rawaf S. Women in Saudi Arabia and the Prevalence of Cardiovascular Risk Factors: A Systematic Review. J Environ Public Health. 2016;2016:15.

56. El Bcheraoui C, Memish ZA, Tuffaha M, Daoud F, Robinson M, Jaber S, Mikhitarian S, Al Saeedi M, Al Mazroa MA, Mokdad AH, et al. Hypertension and its associated risk factors in the kingdom of saudi arabia, 2013: a national survey. Int J Hypertens. 2014;2014:564679.

57. Alsuwaida A, Alghonaim M. Gender disparities in the awareness and control of hypertension. Clin Exp Hypertens. 2011;33(5):354-7.

58. Ali WM, Al Habib KF, Hersi A, Asaad N, Sulaiman K, Al-Shiek-Ali A, et al. Inhospital complications and 1-year outcome of acute coronary syndrome in patients with hypertension: findings from the 2 nd Gulf Registry of Acute Cardiac Events. East Mediterr. Health J. 2012;18(9):902-10.

59. AkI EA, Gunukula SK, Aleem S, Obeid R, Jaoude PA, Honeine R, Irani J. The prevalence of waterpipe tobacco smokingamong the general and specific populations: a systematic review. BMC Public Health. 2011;11:244.

60. Islam SM, Johnson CA. Correlates of smoking behavior among Muslim ArabAmerican adolescents. Ethn Health. 2003;8(4):319-37.

61. Maziak W, Fouad FM, Asfar T,Hammal F, Bachir EM, Rastam S, Eissenberg T, Ward KD.Prevalence and characteristics of narghile smoking among university students in Syria. Int J Tuberc Lung Dis.2004;8(7):882-9.

62. Azab M, OF K, Alkaraki AK, Eissenberg T, Alzoubi KH, Primack BA. Water pipe tobacco smoking among university students in Jordan. Nicotine Tob Res. 2010;12(6):606-12.

63. Labib N, Radwan G, Mikhail N, Mohamed MK, Setouhy ME, Loffredo C, Israel E. Comparison of cigarette and water pipe smoking among female university students in Egypt. Nicotine Tob Res. 2007;9(5):591-6.
64. Dar-Odeh NS, Abu-Hammad OA. The changing trends in tobacco smoking for young Arab women; narghile, an old habit with a liberal attitude. Harm Reduct J. 2011;8:24.

65. Soweid RA. Lebanon: water pipe line to youth. Tob Control. 2005;14(6):363-4.

66. Nuwayhid IA, Yamout B, Azar G, Kambris MA. Narghile (hubble-bubble) smoking, low birth weight, and other pregnancy outcomes. Am J Epidemiol. 1998;148(4):375-83.

67. Mabry RM, Reeves MM, Eakin EG, Owen N. Gender differences in prevalence of the metabolic syndrome in Gulf Cooperation Council Countries: a systematic review. Diabetic Medicine. 2010;27(5):593-7.

68. Al-Bahlani S, Mabry R. Preventing non-communicable disease in Oman, a legislative review. Health Promot Int. 2014;29(Suppl 1):i83-91.

\section{Submit your next manuscript to BioMed Central and we will help you at every step:}

- We accept pre-submission inquiries

- Our selector tool helps you to find the most relevant journal

- We provide round the clock customer support

- Convenient online submission

- Thorough peer review

- Inclusion in PubMed and all major indexing services

- Maximum visibility for your research

Submit your manuscript at www.biomedcentral.com/submit
C) Biomed Central 